\title{
Research on the Status Quo and Countermeasures of Modern Agriculture Development in Dazhou City
}

\author{
Yexing Sun ${ }^{\mathrm{a}}$, Qianqian $\mathrm{Ma}^{\mathrm{b}}$, Haosheng $\mathrm{Li}^{\mathrm{c}}$, Peng Wu $\mathrm{W}^{\mathrm{d}}$, Li'an $\mathrm{Li}^{\mathrm{e}}$, Zhengwei Xie ${ }^{\mathrm{f}}$, Quanhao Lai ${ }^{\mathrm{g}}$, and Siyi Zhao ${ }^{\mathrm{h}}$, \\ Dazhou Academy of Agricultural Sciences, Dazhou, Sichuan, China
}

\begin{abstract}
Developing modern agriculture, promoting the transformation and upgrading of agriculture, and improving the comprehensive benefits of agriculture are important targets for winning the fight against poverty and the inherent requirements and key links for implementing the rural revitalization strategy. As a large agricultural city in northeastern Sichuan, Dazhou City is facing a crucial period of transition from traditional agriculture to modern agriculture. This paper mainly analyzes the status quo of modern agriculture development in Dazhou and the main constraints it faces, and puts forward reasonable suggestions to provide reference for modern agricultural development in Dazhou.
\end{abstract}

\section{Introduction}

Accelerating the transformation from traditional agriculture to modern agriculture, promoting the organic connection between retail management and modern agricultural development, and focusing on improving the development capacity of small farmers' modern agriculture is the focus of modern agricultural development at this stage [1]. The development of modern agriculture in Dazhou City should adhere to the rural revitalization as the starting point, promote the development of the integration of the first, second and third industries, accelerate the construction of the modern agricultural comprehensive demonstration zone and the characteristic industrial cluster park, and strive to achieve the growth of agricultural production from quantity to quality [2]. The development of factors has shifted from innovation-driven, decentralized layout to cluster mode development, focusing on industrial characteristics, taking the cluster development path [3], and continuously deepening the depth and breadth of industrial integration, thus promoting the better, faster and better development of modern agriculture in Dazhou.

\section{Status Quo of Modern Agriculture Development in Dazhou City}

\subsection{The scale of agricultural product processing enterprises continues to expand}

Since 2011, the scale and quantity of agricultural product processing enterprises in Dazhou have expanded significantly. In terms of the number of processing enterprises, the number of agricultural product processing enterprises above designated size in Dazhou has grown to 149 , and the city has cultivated 4,018 farmer professional cooperatives and 1,661 family farms [4]; From the perspective of enterprise benefits, the main business income of agricultural products processing enterprises above designated size increased from 13.258 billion RMB to 17.228 billion RMB, the main business income increased by 3.97 billion RMB, the total profit increased from 380 million RMB to 709 million RMB, and the total profit increased. It has nearly doubled. Under the situation of structural reform of agricultural supply side, agricultural environmental protection pressure and improvement of quality and efficiency, the agricultural product processing industry continued to show a good development trend.

\subsection{The processing capacity of agricultural products is continuously improved}

At present, Dazhou has successfully created 4 well-known trademarks in China, 50 national geographical indication protection products, 21 national ecological origin protection products, 36 Sichuan famous brand products, and 30 famous Sichuan trademarks [4]. The processing rate of agricultural products has reached $50 \%$, which is nearly half of that of $28.7 \%$ in 2012, and the contribution rate to industrial growth has increased year by year. The city's agricultural products coarse and deep processing enterprises and farmers' professional cooperatives, family farms, large-scale farming and other agricultural products processing and trade income of 26 billion RMB, the commodity rate of $60 \%$. The awareness of "Internet + " in agricultural product processing enterprises has increased, and rural e-commerce has developed rapidly. The city has used the Internet and e-commerce platform to realize online shopping and sales of agricultural products worth 1.36 billion RMB, 506 rural e-commerce service stations 
and 5 county e-commerce integrated service centers. The amount of e-commerce transactions in agricultural products accounts for about $15 \%$ of the e-commerce transaction volume. Through strengthening brand building and diversified production and sales platforms, it has effectively enhanced the visibility and market competitiveness of the city's agricultural product processing enterprises.

\subsection{The development of characteristic agricultural industry continues to grow}

Dazhou City has built more than 3 million mu of industrial bases around the " $3+6$ " characteristic advantageous industries, and has nearly 5,000 mu of experimental bases for breeding and recycling. Vigorously develop high-quality grain and oil industry, and increase infrastructure construction in grain and oil core production areas and demonstration areas. The grain planting area reached 55.8 hectares, grain output reached 2,925,100 t, and oil production reached 333,000 t. Vigorously develop the characteristic livestock and poultry industry, build 749 modern animal husbandry breeding communities, and 165 standardized farms above the municipal level. Vigorously develop the characteristic planting industry, with more than 2.5 million mu of special agricultural planting areas such as high-quality ramie, selenium-enriched tea, Hemerocallis citrina Baroni in Quxian and Chinese herbal medicine. Through the development of the scale of characteristic industries, we will continue to provide high-quality raw material supply for the agricultural product processing industry.

\section{The main constraints to the development of modern agriculture}

\subsection{The contradiction between people and land is prominent, and the utilization rate of agricultural mechanization is not high}

There are few mountains in Dazhou, the fluctuation of the terrain is large, the land is fragmented, the output efficiency of the land is reduced, the land is increased, and the contradiction between people and land is prominent [5-6]. Most mountainous areas are not conducive to the implementation of large-scale production operations and the promotion of large-scale agricultural production machinery. The contribution rate of agricultural science and technology progress in the city is less than $50 \%$, and the comprehensive mechanization rate of major crop cultivation and harvesting is less than $40 \%$. At the same time, with the development of urbanization, the rural manpower structure is unbalanced, the agricultural operators are reduced, the age structure is too large, the cultural quality is not high, and the adoption rate of intelligent and information-based high-performance machinery is not high.

\subsection{The agricultural base is weak, and the characteristics of agricultural products processing are lacking}

The operation of small-scale farmers in the city is the mainstay, the level of large-scale operation is not high, and the agricultural output capacity is insufficient to meet the needs of processing enterprises and diversified markets [7]. The market product structure is single, the product production assimilation rate is high, the leading industry leads the shortage, and the agricultural product production is mainly based on primary products, the quality is high, the characteristic varieties are lacking, the industrial layout is scattered, and the industrial cluster construction is relatively lagging [3]. The contradiction between the small production mode and the intensive, specialized and large-scale operation required for modern agriculture is more prominent, which directly affects the sustainable and healthy development of the agricultural product processing industry in the state.

\subsection{Production standards are different, and the construction of industrial development system lags behind}

Dazhou City has a large number of small and medium-sized enterprises processing agricultural products, and its layout is relatively scattered. There is no uniform production standard, product quality is not guaranteed, and the prices of the same kind of products are different. Social service systems such as R\&D systems and trade associations are compatible with the production and processing of agricultural products. The financial support system, the credit system, the standardization system, the inspection system, the food safety system, the technology extension service system, the quality certification system and the information network system of the agricultural product processing industry are not perfect [8]. In addition, the construction of a modern agricultural industry service system is seriously lagging behind, resulting in information asymmetry between agricultural producers and business operators.

\subsection{The processing enterprise is small in scale and the industrial added value is not high}

The agricultural products processing small and medium-sized enterprises in Dazhou generally have the problems of small production scale and low efficiency, and lack of large-scale brand-name enterprises or enterprise groups with strong competitiveness. The enterprises are insufficiently driven and cannot effectively exert regional radiation-driven effects. At the same time, the processing of agricultural products is mostly primary processing and rough processing production, the industrial chain is short, the products are mostly primary processing, and the integration of the first, second and third industries is not deep [9], and the added value of products is not high. Agricultural production and management are still dominated by scattered farmers, and the scale and intensive production level is low. The management 
system of integrated services such as production, supply and marketing, trade, agriculture, agriculture, science and education has not yet been fully formed, and the deep processing technology and processing equipment of processing enterprises are relatively backward. As a result, the product structure is single, the product quality is uneven, the grade is not high, and the market is not competitive.

\section{Countermeasures and suggestions}

In order to realize the healthy development of modern agriculture in Dazhou City, in the final analysis, it is necessary to proceed from the industrial chain [10], deeply promote the integration and development of agricultural one, two and three industries, and focus on solving the rationalization of the allocation of essential resources such as projects, land, manpower, management, policies, markets and funds in agricultural production and management [11].

In the choice of management projects, it is necessary to carry out agricultural characteristic planting and production projects with good development prospects, realize the effective docking of agricultural products production and marketing, and promote the rapid concentration of agricultural products export and agricultural resources, such as the integration of three products, ecological and environmental protection, and so on, according to the provincial and municipal governments and local governments to encourage and support the policy guidance, the management direction of leading enterprises in agricultural products processing, the demand of agricultural markets, and so on. In terms of production and management mode, it is necessary to strengthen the cultivation of new agricultural management subjects, make full use of "order agriculture", "Internet agriculture", "intelligent agriculture" and so on to encourage large-scale production and management, vigorously cultivate and develop "enterprise base farmers", "enterprise specialized organization base farmers", "company science and technology association organization farmers" and other development models [12]. Constantly extend the industrial production chain and industrial integration, constantly promote the development of modern big data agricultural industry, and realize the rational flow of human, financial and material resources between the agricultural product processing industry chain.

In the input of resource elements, it is necessary to rationally allocate the input of resource elements such as land, manpower, capital, technology, equipment, vigorously develop the intensive processing of agricultural products, extend the chain of agricultural industrialization, realize the value-added of agricultural products, and continuously improve the support capacity and supporting capacity of the cluster. To achieve industrial cluster development, we must focus on the brand effect of enterprises, continuously enhance market competitiveness, strengthen the professional cultivation of agricultural managers, and build a set of efficient and complete "cost-benefit-factor-management" analysis of modern agricultural management. The management system has achieved a good industrial development model and a profitable product for sustainable development.

\section{References}

1. Central Office of the Communist Party of China Office of the State Council 《views on promoting the organic connection between smallholder farmers and modern agricultural development $\rangle[\mathrm{J}]$. Management and Administration on Rural Cooperative, 2019(3): 11-15.

2. G.B. Liu, B. Li. The integration of the three agricultural industries and the development of modern agriculture $[\mathrm{J}]$. Research of Agricultural Modernization, 2019, 40(4): 621-628.

3. L. C. Du. The current situation and development countermeasures of rural food processing industry clustering in china in the new period $[\mathrm{J}]$. Agricultural Economy, 2017(5): 57-58.

4. 《Dazhou Yearbook》 Compilation committee. Dazhou Yearbook [M]. Sichuan Science and Technology Press, 2018, 12.

5. H. Yang, P.F. Zhao. Innovative research on the system of agricultural land use in the process of modern agricultural development-taking Chengdu city, Sichuan province as an example [M]. Rural Economy, 2015(06): 39-43.

6. Y. J. Wang. Talking about the present situation and development countermeasures of modern agriculture in dazhou city [J]. Cultural Geography, 2015(14): 279.

7. Y.P. He, S.C. Wu. Connection is empowerment: practice and thinking of the connection between small farmers and modern agriculture [J]. Rural Economy, 2019(06): 28-37.

8. Q. Zhang, H.J. Huai, N. Sun, A.M. Wang, C.J. Li. Research on the status quo and countermeasures of the development of modern agricultural parks by informatization $[\mathrm{J}]$. Journal of Agricultural Science and Technology, 2019: 1-6.

9. H. M. Sun, J. Zhang, C. R. Yu. Convergence of the three industries and agricultural efficiency advancement: Empirical analysis based on WIOD data [J]. Journal of Chinese Agricultural Mechanization, 2018, 39(11): 100-107.

10. T. Yang. Analysis of agricultural products value chain in agricultural industry chain integration [J]. Commercial Times, 2018(12): 150-152.

11. H.M. Chen. Problems and suggestions in the development of modern agricultural economy-comment on "research on the development of modern agricultural economy" [J]. Edible Fungi of China, 2019, 38(06): 29.

12. B. Y. Wang. The construction path of modern agricultural industry system from the perspective of rural revitalization strategy: comment on the management and management of modern agricultural 
industrialization [J]. Edible Fungi of China, 2019, 38(6): 31 